Invited commentary

\title{
Role of antinutrient metabolites of plant on production of secondary metabolites and human health
}

\author{
Raman Dang \\ Registrar, Delhi Pharmaceutical Sciences and Research University (DPSRU), \\ Mehrauli-Badarpur Road, Puspvihar Sector 3, New Delhi-110017, India
}

Received April 15, 2018: Revised May 30, 2018: Accepted June 3, 2018: Published online June 30, 2018

The secondary metabolites are important constituents of plants for the human beings, for most of the population in the World believe on plant based medicines. These phytoconstituents serve as primary important molecules in modern medicine (Ncube et al., 2008). Many people still depend on the traditional medicine for their preliminary healthcare and treatment (Bannerman et al., 1986). All these treatments mainly depend on the phytoconstituents present in the plants. These concepts force to discover modern medicines in early 19th century where plants were scientifically proved its efficacy due to particular chemical present. Hence, drug discovery from the plant sources gains maximum momentum and importance in the era of modern medicine system. Plants produce huge number of different chemical compounds which are broadly categorized into primary and secondary metabolites. Primary metabolites are essential for the growth of the plants like sugar, proteins, amino acid, etc. Secondary metabolites are the products that are considered as waste substances of plants, which are deposited inside the plant bodies in various parts, and provide protection to the plants from attacks of microorganisms, attracting pollinators, etc. These secondary metabolites are relatively produced in low quantities in plants but have significant economic and medicinal value to humans. High concentration of secondary metabolites present in plants indicates more resistant to diseases. Various scientific research evidences proved that the therapeutic efficacy and pharmacological actions are mainly by the action of secondary metabolites. Not only that, they are also useful in preparation of various dyes, preparation of agrochemical insecticides, availability of raw materials to industries, for preparation of perfumes, cosmetics, coloring and flavoring agents. The main basic mechanism for plant growth and production of plant metabolites are the uptake of nutrients from the soil and the environment.

Nutrients are the substances that are used by plants to survive, grow, and reproduce. Broadly, nutrients are two categories: macronutrients and micronutrients. Macronutrients (carbohydrates, fats, proteins, water) are required in more quantity and used primarily to generate energy and to incorporate into tissues for

\footnotetext{
Author for correspondence: Dr. Raman Dang

Registrar, Delhi Pharmaceutical Sciences and Research University (DPSRU)Mehrauli-Badarpur Road, Puspvihar Sector 3, New Delhi110017, India

E-mail: dangraman2000@yahoo.co.in

Tel.: +91-9945846106
}

Copyright @ 2018 Ukaaz Publications. All rights reserved.

Email: ukaaz@yahoo.com; Website: www.ukaazpublications.com growth and repair. Micronutrients though needed in smaller amounts, they play an important biochemical and physiological roles in cellular processes. All these nutrients are organic and inorganic compounds. Organic compounds contain carbon, whereas inorganic compounds include $\mathrm{Fe}, \mathrm{Se}, \mathrm{Zn}$, etc. Inadequate or excess amounts of essential nutrients, cause diseases that interfere with absorption. A deficiency state of these nutrients caused a compromise in growth, survival and reproduction. The absorption of nutrients by plants in the form of macro or micronutrients are greatly depends on the demographic location and cultural conditions and based on the plant secondary metabolites which are also accumulated in the plant bodies. Many scientific literatures are evident on that (Das et al., 2017; Das and Dang, 2017; Das et al., 2016). Excess amount of nutrients causes the plant to show harmful effects (Ensminger, 1994), such nutrients are called antinutrients.

Antinutrients are the compounds or substances that act to reduce nutrient intake, digestion, absorption and utilization and also produce adverse effects. They are also known as antinutritional factors. Seeds of legumes and other plant sources contain wide varieties of antinutrients (raw state) that are potentially toxic. The major antinutrients are toxic amino acids, saponins, cyanogenic glycosides, tannins, phytic acid, gossypol, oxalates, goitrogens, lectins (phytohaemagglutinins), protease inhibitors, chlorogenic acid and amylase inhibitors. The concentration of these antinutrients in plant sources vary with the species of plant, cultivar as well as processing methods (Akande et al., 2010). The toxic amino acids act antagonistically towards certain nutritionally important amino acids (Liener, 1980). For example, mimosine, a toxic non-protein amino acid structurally similar to tyrosine, is contained in the legume, Leucaena leucocephala (D'Mello, 2000). This constituent also shows adverse effect on mammals. The major symptoms of toxicity are poor growth, loss of hair and wool, lameness, mouth and goiter. Djenkolic acid (sulphur containing amino acid, similar to cystine) is present in Pithecolobium lubatum beans in free state which is not degraded in the animal body as a result, it crystallizes out in the kidney and excreted through kidney (Enwere, 1998). Saponins are triterpene and steroidal glycoside compounds present in kidney beans, soybeans, ground nuts. Excess saponin content adversely affects animals, causing erythrocyte haemolysis, reduction of blood and liver cholesterol, depression of growth rate, inhibits enzyme activity and cause a reduction in nutrient absorption (Cheeke, 1971). Cyanogenetic glycosides are mainly present in kidney beans, lima beans in large concentrations. The main hydrolytic compound is hydrocyanic acid which is liberated by enzyme action, is very toxic at low concentrations to animals. It causes central nervous system 
dysfunction, respiratory failure and cardiac arrest (D'Mello, 2000). Tannins are high molecular weight water soluble phenolic compounds. Tannins may form a less digestive complex with dietary proteins and may bind and inhibit the endogenous protein, such as digestive enzymes (Kumar and Singh, 1984). They are of mainly two types, i.e., hydrolysable and condensed tannins. Condensed tannins are responsible for the testa bound trypsin inhibitor activity of fababeans (Helsper et al., 1993). Hence, tannins interfere with digestion by displaying antitrypsin and antiamylase activity. Phytic acid is one more major antinutrient that occurs naturally throughout the plant kingdom. It is present in major legumes and oilseeds. They accumulate in the storage side in seeds and forms chelates (complex phytate) (Erdman, 1979) with several metal ions and form insoluble complexes that are not absorbed by the gastro intestinal tract (GIT). Gossypol, a naturally occurring polyphenolic occurs in cotton seeds. Gossypol binds with the reactive epsilon amino group of lysine during heat processing and reduces lysine availability (Robinson, 1991). It causes a depressed appetite, loss of weight, laboured breathing and cardiac irregularity. Lectins are glycoprotein containing antinutrient, widely distributed in legumes and some certain oil seeds. It can directly bind to the intestinal muscosa and interferes with the absorption and transportation of nutrients (Santiago et al., 1993). Chlorogenic acid, a tannin like compound present in sunflower meal and inhibits activity of digestive enzymes including trypsin, chymotrypsin, amylase and lipase (Cheeke and Shull, 1985). All the above antinutrients inhibit or resist the nutrient uptake by the plants and this results in improper growth, eventually affecting the production of plant secondary metabolites. Titration methods are used to determine the oxalates and phytates, whereas alkaloids, saponins and tannins are determined by other specific methods. With these estimation methods, the activities of antinutrients are reduced and improve both the content of plant secondary metabolites as well human health.

Most of these antinutritional factors are present in foods of plant origin. Thus, their presence in foods may induce undesirable effects in human population above a limit. The harmful effects may also be due to the products of metabolism of these compounds. These antinutritional factors as well as their metabolites may have beneficial health properties, if present in smaller quantities (Gemede and Ratta, 2014). Further, antinutritional factors such as nitrates, oxalates, phytates, cyanogenic glycosides and tannins in vegetables may disturb absorption of micronutrients and, makes them unavailable. Thermal processing of leafy vegetables through boiling, cooking and blanching before consumption is very helpful in reducing the level of antinutrients (Natesh et al., 2017).

In the journey from traditional era to the modern scientific era, scientific journals have played a vital role by publishing systematic scrutinized and double blind reviewed good quality papers. Currently lots of online journals are available but very few are maintaining standard quality. Getting good quality research works with innovative scientific concepts confined in the form of standard manuscripts are not easy. Not only that, selection of manuscripts by the editorial board as well as the services of efficient, experienced and unbiased reviewers is also a team works required for the success of a journal. The journals should provide a solid platform for inspiration to the scientists, students and young researchers in particular. Of late "Annals of Phytomedicine" is a prestigious multidisciplinary journal where plant science linked with all the disciplines such as chemistry, pharmacology, modern medicine, biochemistry, biotechnology, molecular biology, plant tissue culture and statistics work harmonically. This broad multidisciplinary concept is the key success to this journal for running smoothly in this difficult and challenging world. Quality of papers that are publishing in this journal, keeps high within a small span of years with prestigious abstracting and indexing. Further, the journal is ahead of Thomson Reuters indexing and wishing for successful long journey. I am very happy to acknowledge and share my article in this journal and appeal to all the researchers that "Annals of Phytomedicine: An International Journal" is the right forum for publication of their research papers.

\section{References}

Akande, K.E.; Doma, U.D.; Agu, H. and Adamu. H.M. (2010). Major antinutrients found in plant protein sources: Their effect on nutrition. Pakistan Journal of Nutrition, 9(8);827-832.

Bannerman, P.G.C.; Mirsky, R.; Jessen, K.R.; Timpl, R. and Duance, V.C. (1986). Light microscopic immunolocalization of laminin, type IV collagen, nidogen, heparan sulphate proteoglycan and fibronectin in the enteric nervous system of rat and guinea pig. J. Neurocytol., 15:432-443.

Cheeke, P.R. (1971). Nutritional and physiological implications of saponins: A review. Can. J. Anim. Sci., 51:621-623.

Cheeke, P.R. and Shull, L.R. (1985). Tannins and polyphenolic compounds. In: Natural toxicants in feeds and poisonous plants. AVI Publishing Company, USA.

Das, K.; Rekha, R; Ibrahim, M.A.; Yahya Ahmed, S. and Dang, R. (2017). Effect of demographic location on Phlebodium decumanum (Willd.) J. Sm. for its phytoconstituents content and establishment of antioxidant and novel anthelmintic activity of its aqueous and methanolic leaf extracts. Ann. Phytomed., 6(1):101-106.

Das, K. and Dang, R. (2017). Influence of demographic location and solvent extraction on pharmacognostical assessment and identification of conessine content in different parts of Holarrhena antidysentrica through HPTLC analysis. Indian J. of Pharmaceutical Education and Research, 51(3):427-435.

Das, K.; Deb, S.; Karanth, T.; Upreti, S. and Dang, R. (2016). Effect of cultural condition on element contents in raw material vis-à-vis impact of solvent nature on estimation of phytochemicals and screening of anthelmintic activity of Melia dubia Cav. leaf. Ann. Phytomed., 5(2):58-68.

D'Mello, J.P.F. (2000). Antinutritional factors and mycotoxins. In: Farm animal metabolism and nutrition. CAB International Wallingford, UK, pp:383-403.

Ensminger, A.H. (1994). Foods and nutrition encyclopedia. CRC Press. pp:527.

Enwere, N.J. (1998). Foods of plant origin: Processing and utilization with recipes and technology profiles. Afroorbis Publications Ltd., Nsukka, pp:301.

Erdman, J.W. (1979). Oilseed phytates: Nutritional implications. J. Am. Oil Chemist. Soc., 56:736-741. 
Habtamu, Fekadu Gemede and Negussie Ratta (2014). Antinutritional factor in plant foods: Potential health benefits and adverse effects. International Journal of Nutrition and Food Sciences, 3(4):284 289.

Helsper, J.P.; Hoogendijk, J.M.; Van Norel, A. and Burger-meyer, K. (1993). Antinutritional factors in fababeans (Vicia faba L.) as affected by breeding toward the absence of condensed tannins. J. Agric. Food Chem., 41:1058-1061.

Kumar, R. and Singh, M. (1984). Tannins: Their adverse role in ruminant nutrition. J. Agric. Food Chem., 32:447-453.

Liener, I.E. (1980). Heat labile antinutritional factors. In: Advances in legume science, (Editors: R.J. Summerfield and A.H. Bunting), Kew London, Royal Botanic Gardens, pp:157-170.
Natesh, H.N.; Abbey, L. and Asiedu, S.K. (2017). An overview of nutritional and antinutritional factors in green leafy vegetables. Horticult. Int. J., 1(2):00011. DOI: 10.15406/hij.2017.01.00011

Ncube, N.S.; Afolayan, A.J. and Okoh, A. (2008). Assessment techniques of antimicrobial properties of natural compounds of plant origin: Current methods and future trends. Afr. J. Biotech., 7:1797-1806.

Robinson, E.H. (1991). Improvement of cotton seed meal protein with supplemental lysine in feeds for channel catfish. J. Applied Aquac., 1:1-14.

Santiago, J.G.; Levy-Benshimol, A. and Carmona, A. (1993). Effect of Phaseolus vulgaris lectins on glucose absorption, transport and metabolism in rat everted intestinal sacs. J. Nutr. Biochem., 4: 426-430. 


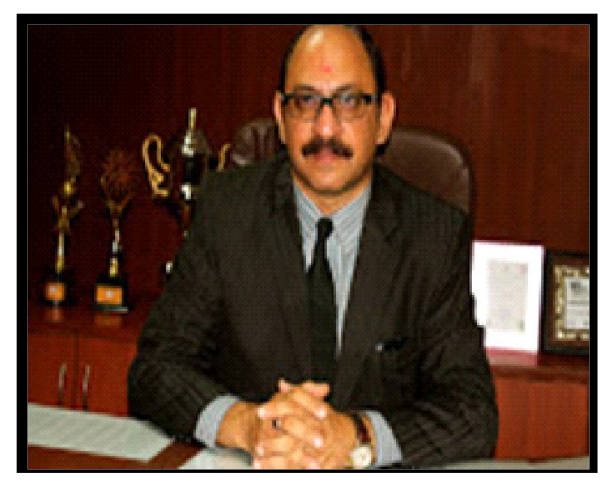

Professor Raman Dang

Registrar, Delhi Pharmaceutical Sciences and Research University (DPSRU),

Mehrauli-Badarpur Road, Puspvihar Sector 3, New Delhi-110017, India

Professor Raman Dang (M.Pharm, Ph.D., MBA, FAELS), Registrar, DPSRU, New Delhi, India is a dynamic, hardworking, enthusiastic professional and responsible person in the field of Pharmaceutical Sciences. He has proven leadership abilities in working as a team, handling multiple tasks, great adaptability to any enterprise's environment.

He is having total 25 years of Teaching and Research Experience in that, 4 years as Principal in Krupanidhi College of Pharmacy, Bangalore, India. He is specialized in the area of cultivation and standardization of medicinal plants, tissue culture of endangered plants, pharmacological activities of plant extracts, formulation and clinical investigation of plant products. In his career, he has guided 6 Ph.D. students, 32 M.Pharm. students and co-guided 12 M. Pharm. students. Not only academic, he has proved his ability in Dabur Industry, Ranbaxy where he worked as Research Associate for several months. He is active M. Pharm. and Ph.D. Examiner, Paper setter, Evaluator at various universities throughout India and appointed as chief and Deputy Chief for Post Graduate and Graduate University Examinations. Currently, he holds the prestigious BOS Chairman for P.G. courses, nominated by the Rajiv Gandhi University, Bangalore and is Joint Secretary for APTI (South zone).

Awards and Acclaims: His carrier reflected with various prestigious awards and acclaims in which Gold Medal for topping in Karnataka State for the Award of Diploma of Pharmacy, 1988, Best Paper Award at IPC, Indore. $1999,1^{\text {st }}$ runners up award at $61^{\text {st }}$ FIP conference, held at Singapore, 2001 and Best Oral paper presentation award at the International Conference on Botanicals, held at Kolkata during $25^{\text {th }}$ and $26^{\text {th }} \mathrm{Feb}, 2005$ are important. He has delivered lectures as invited speaker and chaired more than 12 scientific sessions for high profile scientific speakers in many National and International conferences. He was deputed as International Scientific Advisor for many conferences. Appointed Chairperson for RAKAPTI International convention at Rasal Al Khaimah, UAE.
Paper presentation: He has presented more than 60 research papers in various National and International seminars, conferences and symposiums and organized workshops and conferences. He has appointed as International coordinator for GOFMAP that is having 113 countries under its belt.

Publications: He has more than 60 research papers, 15 review papers, 3 conference proceedings in various peer-reviewed National and International journals of repute. Apart from that, he has more than 30 general articles, contributed in various magazines, especially in APTI bulletin. He has contributed 2 book chapters in edited books, entitled "Recent progress in Medicinal Plant", Vol-19, Published by Studium Press, LLC, USA, ISBN: 0-9656038-5-7.

Membership of bodies: He is associated with various prestigious bodies with life membership, among that membership in FIP, Society of Ethanopharmacology, APTI are highly appreciated. He serves as active member for academic council and faculty of pharmacy.

Editors and reviewers: He is serving as editorial board and reviewer committee member for more than 15 peer-reviewed and National and International journals.

Special credentials: With his active efforts, the college accreditated with quality certification by "The National Assessment and Accreditation Council (NAAC)" for maintaining sustained and uplifted quality education and actively involved in the finalizing of the MOS's between Teleradiology, Wipro and Green Chem. He serves as an expert committee and scrutiny member for various research projects under Rajiv Gandhi University of Health Sciences, Bangalore, Inida. 